\title{
Incremental Introduction of Organocatalytic Activity into Conformationally Engineered Porphyrins
}

\author{
Marc Kielmann, ${ }^{[a]}$ Nitika Grover, ${ }^{[a]}$ Werner W. Kalisch ${ }^{[a]}$ and Mathias O. Senge ${ }^{*[a]}$
}

\begin{abstract}
To study the correlation of macrocycle nonplanarity and catalytic activity of free base porphyrins in detail, a series of six tetraphenylporphyrins with graded degree of $\beta$-ethyl substitution (' $\mathrm{H}_{2} \mathrm{Et}_{\mathrm{x}}$ TPPs' 1-6; $\mathrm{x}=0,2,4,6,8$ ) was applied in organocatalyzed reactions. The macrocycles display incrementally increasing nonplanarity due to repulsive periinteractions. This creates an out-of-plane vector and better accessibility of the core amine and imine groups as the number of alkyl substituents increases. Following such a molecular engineering approach, the inner core system could be used to activate small molecules as a result of significant saddle distortion. The potential organocatalyst ' $\mathrm{H}_{2} \mathrm{Et}_{\mathrm{x}}$ TPPs' were used in benchmark sulfa-Michael reactions and we found a distinct relationship between nonplanarity and conversion. These observations were attributed to the combined effect of enhanced basicity and increased $\mathrm{H}$-bonding potential that could facilitate bifunctional organocatalysis. Ultimately, density functional theory (DFT) calculations were performed on 1-6 to monitor some electronic properties of the title compounds.
\end{abstract}

\section{Introduction}

Porphyrins are multifaceted macrocyclic compounds and used to illustrate advances for example in chemistry, biochemistry, physical chemistry, and beyond. ${ }^{[1]}$ They are omnipresent in nature (e.g., in pigment-protein complexes and metalloproteins; hemes) where a close interplay between their stereochemistry and activity has been observed. ${ }^{[2]}$ Thanks to the porphyrin skeleton's flexibility, manipulation of the macrocycles' conformations allows fine-tuning of their physicochemical traits. ${ }^{[3]}$ This includes binding properties, catalytic activity, and chemical reactivity in general, ${ }^{[2,4,5]}$ and inspired us to advance molecular engineering approaches based on conformational control in tetrapyrroles. ${ }^{[4,6]}$

In planar porphyrins, the pyrrole $\mathrm{N} / \mathrm{N}-\mathrm{H}$ moieties are considered as hidden within the inner core system and inaccessible for any supramolecular use as they are shielded by the surrounding macrocycle. This prevents the formation of hydrogen bonding complexes $\mathrm{N}-\mathrm{H} \cdots \mathrm{X}$ with acceptor molecules $\mathrm{X}$ or deprotonation of donor molecules. However, methods exist to modulate the tetrapyrrole conformations and to reshape the vector of $\mathrm{N} / \mathrm{N}-\mathrm{H}$ orientation outwards, thus increasing their availability and reactivity. ${ }^{[6 a, b, 7]}$ One such strategy is the use of saddle-distorted porphyrins ${ }^{[8]}$ and today the class of $2,3,5,7,8,10,12,13,15-$ $17,18,20$-dodecasubstituted porphyrins is often applied for studies in this area. ${ }^{[9]}$ Furthermore, they are often accessible through facile syntheses and conformational tailoring. ${ }^{[6,10,11]}$ While these species are highly basic and form hydrogen-bonded complexes $\mathrm{N}-\mathrm{H} \cdots \mathrm{X}$ under participation of the pyrrolic $\mathrm{N}-\mathrm{H}$ groups in the core, the planar counterparts often remain inert. ${ }^{[6 a, b, 12]}$

Saddle-shaped $\quad 2,3,7,8,12,13,17,18$-octaethyl-5,10,15,20tetraphenylporphyrin $\left(\mathrm{H}_{2} \mathrm{OETPP}, \mathbf{1}\right)$ is severely nonplanar ${ }^{[12 g]}$ and, as we have shown, organocatalytically active. ${ }^{[6 b]}$ Moreover, a mostly structural, comparative study by our group focused on the ' $\mathrm{H}_{2} \mathrm{Et}_{\mathrm{x}}$ TPP' series that included 1 and the related compounds 2-5. ${ }^{[7]}$ Therein, we elaborated the steric consequences of incremental peripheral substitution on the macrocycles and the effects on physicochemical properties. ' $\mathrm{H}_{2} \mathrm{Et}_{\mathrm{x}}$ TPPs' are structural hybrids of 5,10,15,20-tetraphenylporphyrin $\left(\mathrm{H}_{2} \mathrm{TPP}, 2\right)$ and 2,3,7,8,12,13,17,18-octaethylporphyrin $\left(\mathrm{H}_{2} \mathrm{OEP}\right)$, which become increasingly nonplanar in the order: $\mathrm{H}_{2}$ TPP $(2)<7$,8-diethyl5,10,15,20-tetraphenylporphyrin $\left(\mathrm{H}_{2} \mathrm{DETPP}, \quad 3\right)<7,8,17,18-$ tetraethyl-5,10,15,20-tetraphenylporphyrin $\left(\mathrm{H}_{2} t\right.$ TETPP, 4) < 2,3,7,8-tetraethyl-5,10,15,20-tetraphenylporphyrin $\quad\left(\mathrm{H}_{2}\right.$ CTETPP, 5) < 2,3,7,8,17,18-hexaethyl-5,10,15,20-tetraphenylporphyrin $\left(\mathrm{H}_{2} \mathrm{HETPP}, \mathbf{6}\right)<\mathrm{H}_{2}$ OETPP (1) because the central $\mathrm{N}-\mathrm{H}$ donors are severely forced out-of-plane as $\beta$-substitution increases (Figure 1). However, after establishing their structural landscape, we are now interested in the effects of out-of-plane conformations on binding properties and catalytic activation. ${ }^{[6 a, b]}$ [a] M. Kielmann, Dr. N. Grover, Dr. W. W. Kalisch, Prof. Dr. M. O. Senge

School of Chemistry, SFI Tetrapyrrole Laboratory, Trinity Biomedical Sciences Institute

Trinity College Dublin, the University of Dublin

152-160 Pearse Street, Dublin 2, Ireland

E-mail: sengem@tcd.ie

Twitter:@mathiassenge

http://chemistry.tcd.ie/staff/people/mos/Home.html 

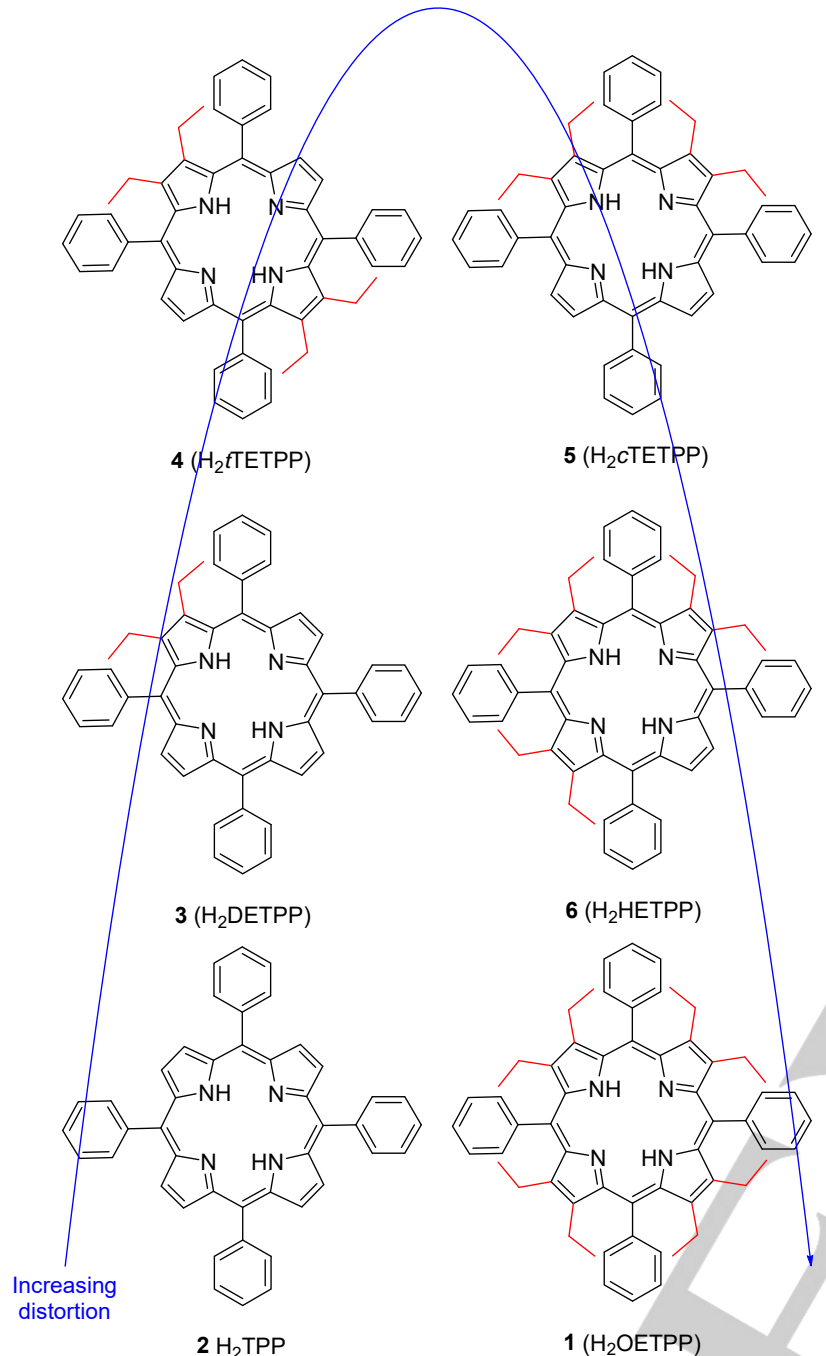

1 ( $\left.\mathrm{H}_{2} \mathrm{OETPP}\right)$

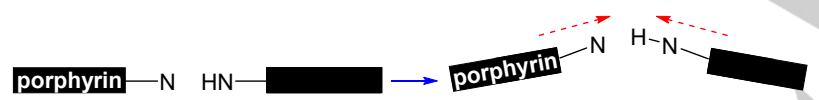

Figure 1. ' $\mathrm{H}_{2} \mathrm{Et}_{x}$ TPPs' 1-6 with graded degrees of $\beta$-ethyl substitution and incrementally increasing nonplanarity. ${ }^{[7]}$

Recently, for the first time, we were able to utilize metal-fee (free base) and $\mathrm{N}$-methylated porphyrins as organocatalysts in Michael reactions and suggested a bifunctional mode of activation (Figure 2). $\left.{ }^{[6]}\right]$ Specifically, 1 gave the best results and catalyzed a sulfa-Michael addition of tert-butyl benzylmercaptan (7) to phenyl vinyl sulfone (8) to afford adduct 9 quantitatively; a reaction susceptible to bifunctional catalysis (Scheme 1 ). This was also compared to the performance of various common bases, including 4-dimethylaminopyridine (DMAP), triethylamine (TEA), and 1,8-diazabicyclo[5.4.0]undec-7-ene (DBU). While the use of weak amine bases failed to promote the reaction, the conversion using 1 was comparable to that of TEA. However, in order to obtain a better understanding and additional proof for the likely bifunctional mode of activation, we herein designed a case study where conversion is correlated with the stepwise accessibility of both Lewis acidic amine and Lewis basic imine moieties. That is because an understanding of these correlations will ultimately allow us to design porphyrins that will surpass the performance of standard bases due to their greater tunability and superior potential for functionalization.

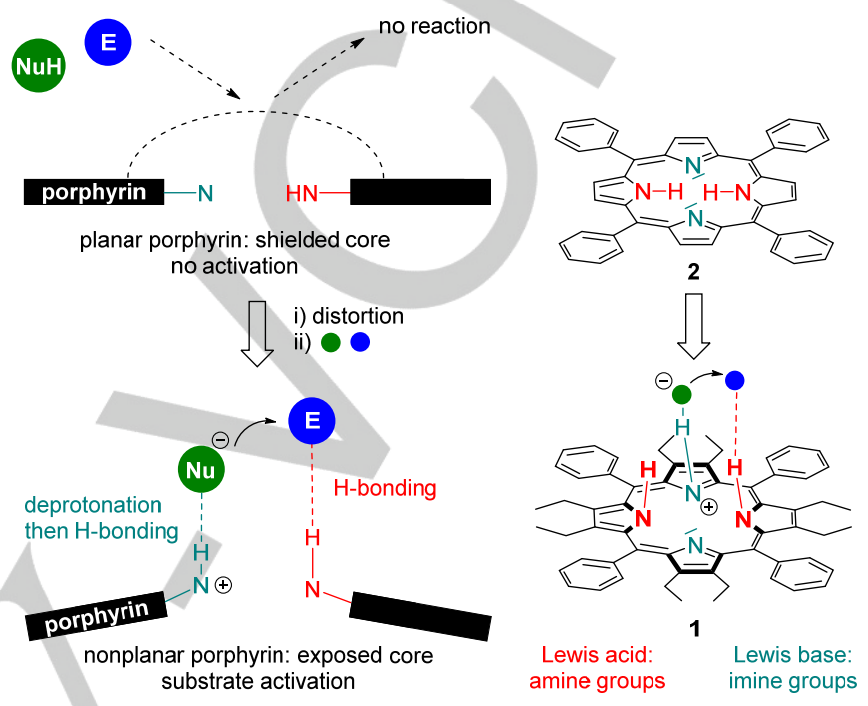

Figure 2. Organocatalytic activity of distorted porphyrins. The shielded core of 2 and porphyrins with minimal peripheral substitution $(e . g ., 3,4)$ is unable to bind/activate small molecules. When steric strain is increased (for example through $\beta$-substitution in $\mathbf{5}, \mathbf{6}$, and $\mathbf{1}$ ), the bifunctional core is exposed and becomes available for intermolecular interactions (deprotonation, $\mathrm{H}$ bonding). ${ }^{[6 \mathrm{~b}]}$

\section{Results and Discussion}

In a few words, the structural assessment of 1-6 points at an inner core system (i.e. $\mathrm{N} / \mathrm{N}-\mathrm{H}$ groups) that becomes more and more exposed as one progresses from $\mathbf{2} \rightarrow \mathbf{1} .^{[7 a]}$ This was proven by a structural evaluation (e.g., $\Delta 24$ values, pyrrole tilts) and also indicated through diagnostic spectroscopic parameters (e.g., bathochromic shifts in the Soret and $Q$ bands of the electronic absorption spectra, ${ }^{[13]}$ deshielded $\mathrm{N}-\mathrm{H}$ protons as seen in ${ }^{1} \mathrm{H}$ NMR spectra) (Table 1).

Increasing $\Delta 24$ values (the average deviation of the macrocycle atoms from the 24-atom least-squares plane, a measure of overall macrocycle distortion) and pyrrole tilts indicate that the potentially catalytically active $\mathrm{N} / \mathrm{N}-\mathrm{H}$ sites are displaced above and below the mean-plane, respectively, and rotated in a way that the $\mathrm{N}-\mathrm{H}$ donors point out of the macrocycle. At the same time, drastic red-shifts in the Soret and $Q$ bands along with increasing chemical shifts serve as a measure of severe macrocyclic distortion in solution. This formally resembles a stepwise molecular reshaping process and we have shown that this is a prerequisite for the ability to activate reaction components, as exemplified by $1 .{ }^{[6 b]}$ However, taking the complete library 1-6 into account allowed us to trace the 
process of inducing catalytic activity into the tetrapyrroles endto-end. Herein, by closing the gap between 2 (inactive) and 1 (highly active), we were able to seamlessly proof the key role of nonplanar conformations in organocatalysis.

Table 1. Selected structural and spectroscopic parameters of ' $\mathrm{H}_{2} \mathrm{E}_{\mathrm{tx}}$ TPPs' $1-6^{[7 a]}$

\begin{tabular}{lllll}
\hline Compound & $\Delta 24[\bar{A}]^{[a]}$ & $\begin{array}{l}\text { av. pyrrole } \\
\text { tilt [deg.] }\end{array}$ & $\lambda_{\max [\mathrm{nm}]^{[\mathrm{b}]}}$ & $\delta[\mathrm{ppm}]^{[\mathrm{c}]}$ \\
$\mathbf{2}$ tricl. $^{[14]}$ & 0.05 & 4.0 & 417,647 & -2.77 \\
$\mathbf{3}$ & 0.10 & 4.3 & 420,645 & $-3.04 /-2.45$ \\
$\mathbf{4}$ & 0.29 & 15.0 & 426,649 & -2.60 \\
$\mathbf{5}$ & 0.38 & 20.4 & 433,672 & -2.38 \\
$\mathbf{6}$ & 0.46 & 24.0 & 444,685 & -2.23 \\
$\mathbf{1}$ & 0.54 & 31.2 & 456,706 & -2.04 \\
\hline
\end{tabular}

[a] Average deviation from the least-squares plane of the 24-macrocycle atoms. [b] Soret and long wavelength $\mathrm{Q}$ absorption bands in $\mathrm{CH}_{2} \mathrm{Cl}_{2}(+1 \%$ $\mathrm{NEt}_{3}$ ). [c] ${ }^{1} \mathrm{H}$ NMR chemical shifts of the inner core protons in $\mathrm{CDCl}_{3}$.

Reviewing the sulfa-Michael reaction of $\mathbf{7}$ and $\mathbf{8}$ from our initial studies on catalytically active distorted porphyrins, we assumed that this system may also prove to be susceptible to activation by 1-6 (Scheme 1). ${ }^{[6 \mathrm{~b}]}$

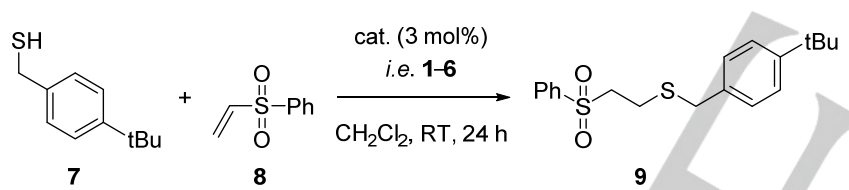

gradually increasing conversion?

Scheme 1. Sulfa-Michael test reaction to compare the catalytic activity of 1-6

And indeed, comparative screening of tetrapyrroles 1-6 under concentrated conditions $\left(\mathrm{c}_{\text {[cat. }}=7.1 \times 10^{-2} \mathrm{M}\right)$ revealed a close correlation between conversion and distortion (Table 2). As expected, a blank sample without catalyst did not show any product formation. At the same time, almost planar $\mathrm{H}_{2}$ TPP (2) and $\mathrm{H}_{2}$ DETPP (3) failed to promote the reaction. When $\mathrm{H}_{2} t$ TETPP (4) was applied, which has a noticeable degree of saddle distortion, catalytic activation started to become measurable, resulting in a conversion of $3 \%$. While having the same number of $\beta$-ethyl groups, the pyrrole units in $\mathrm{H}_{2}$ CTETPP (5) point significantly more out of the mean-plane than in $\mathbf{4}$, which gave $50 \%$ product. Initial screening of $\mathrm{H}_{2} \mathrm{HETPP}(6)$ and $\mathrm{H}_{2}$ OETPP (1) under these conditions showed almost identical conversions of $97 \%$ and $>98 \%$, respectively. To distinguish the competence of $\mathbf{6}$ vs. 1, diluted conditions were applied $\left(\mathrm{c}_{\text {[cat.] }}=\right.$ 3.6.10 $10^{-3} \mathrm{M}$ ). As expected, we were now able to discriminate their activity as significantly different conversions became evident for $6(8 \%)$ and the most distorted species $1(80 \%)$. The outcome of this comparative screening approach is clearly in favor of the points we were aiming to make: as distortion increases, the inner core system becomes more available to activate reagents 7 and 8. Based on our previous proposal, we ascribe this to an escalating willingness of the more nonplanar macrocycles to form hydrogen bonds with $\mathbf{8}$ and to deprotonate $\mathbf{7}$ (as illustrated in Figure 2). ${ }^{[6 a]}$

Table 2. ${ }^{[a]}$ Results of the catalytic screening of ' $\mathrm{H}_{2} \mathrm{Et}_{\mathrm{x}}$ TPPs' $1-6 .{ }^{[\mathrm{a}]}$

\begin{tabular}{lll}
\hline Catalyst & Conv. [\%] $\left(\mathrm{c}_{\text {[cat.] }}=7.1 \cdot 10^{-2} \mathrm{M}\right)$ & Conv. [\%] $\left(\mathrm{c}_{[\text {cat. }}=3.6 \cdot 10^{-3} \mathrm{M}\right)$ \\
\hline Blank & Traces & Traces \\
$\mathbf{2}$ & Traces & Not performed \\
$\mathbf{3}$ & Traces & Not performed \\
$\mathbf{4}$ & 3 & Not performed \\
$\mathbf{5}$ & 51 & Not performed \\
$\mathbf{6}$ & 97 & 8 \\
$\mathbf{1}$ & $>98^{[6 \mathrm{~b}]}$ & 80 \\
\hline
\end{tabular}

[a] Full experimental details can be found in the Experimental Section.

The availability of the inner core $\mathrm{N} / \mathrm{N}-\mathrm{H}$ entities for intermolecular contacts in nonplanar porphyrins is certainly a result of the induction of an out-of-plane vector. However, while this correlation is rather coherent, we were also interested in how saddle distortion and formal $\beta$-ethylation would affect their electronic properties. As such, we decided to investigate whether enhanced imine basicity and amine acidity in the order $\mathbf{2} \rightarrow \mathbf{1}$ would be mirrored by trends in the charge densities assigned to the $\mathrm{N} / \mathrm{N}-\mathrm{H}$ functional groups.

In order to gather insight into the compounds' electronic properties, DFT calculations were performed on 1-6 using a B3LYP functional and a $6-31 \mathrm{G}(\mathrm{d}, \mathrm{p})$ basis set. ${ }^{[15]}$ Coordinates for geometry optimizations were taken from previously known crystal structures (CCDC:[16] PHPOR10 (2); TATPOT01 (3); TATPUZ01 (4); TATQAG01 (5); TATQEK01 (6); SATQOU (1)). ${ }^{[7 a, 12 g, 14]}$ Figure 3 compiles the calculated Mulliken charges that were assigned to the $\mathrm{N}^{\mathrm{a} / \mathrm{b}} / \mathrm{N}-\mathrm{H}^{\mathrm{a} / \mathrm{b}}$ atoms of the porphyrins in detail and it was found that the charge densities at the inner core amine and imine moieties varied only slightly depending on the number of peripheral ethyl groups. For better comparison, the individual values for $\mathrm{N}^{\mathrm{a} / \mathrm{b}}$ and $\mathrm{N}-\mathrm{H}^{\mathrm{a} / \mathrm{b}}$ were also averaged.

Two trends became evident upon incremental $\beta$-ethyl substitution: (i) decreasing charge densities at the amine hydrogen atoms and (ii) increasing charge densities at the imine moieties. For example, the average partial positive charges of inner core $\mathrm{N}-\mathrm{H}^{\mathrm{a} / \mathrm{b}}$ hydrogen atoms in $\mathrm{H}_{2} \mathrm{OETPP}(1)$ were lower than in $\mathrm{H}_{2}$ TPP (2) (0.374 vs. 0.402). In contrast, 2 had a more pronounced av. partial negative charge at the core imine functions than 1 (-0.565 vs. -0.537). Therefore, an isolated assessment of only these electronic parameters would in principal suggest that 2 should have more favorable acid/base properties than 1 (Figure 3). However, in general, there are two main aspects to the catalytic activity of nonplanar porphyrins: a steric factor (tied to the core accessibility to substrates) and an 
electronic factor (tied to the acid/base properties of the inner core system). Catalytic screening revealed that de facto, $\mathrm{H}_{2}$ OETPP (1) exhibits the best performance (Table 2). As such, the charge densities provided by the DFT model fail to mirror the trends that were observed in catalytic activity. One reason might be that the changes in partial charges are rather small. Hence, they may simply be outperformed by the increasing core availability. This would suggest that in the ' $\mathrm{H}_{2} \mathrm{EtxTPP}$ ' series, a nonplanar geometry may be of more significance than favorable electronic properties of the $\mathrm{N} / \mathrm{N}-\mathrm{H}$ atoms. However, we have previously shown that electron-rich macrocycles are better organocatalysts than electron-poor species. ${ }^{[6]}$ Again, this shows that differentiating the influence of steric and electronic factors in nonplanar porphyrins is nontrivial and both cannot be treated as separate entities. ${ }^{[17]}$ Moreover, additional factors may contribute to the observed changes in partial charges of the inner core, such as destabilization of the aromatic system due to macrocyclic deviation from an ideal planar shape. As a consequence, the results of the DFT calculations appear to be unable to reflect all aspects that contribute to an increased organocatalytic activity. One issue that remains is the difficulty of finding porphyrin compounds that have the same conformation but clearly differentiated electronic structures or vice versa.

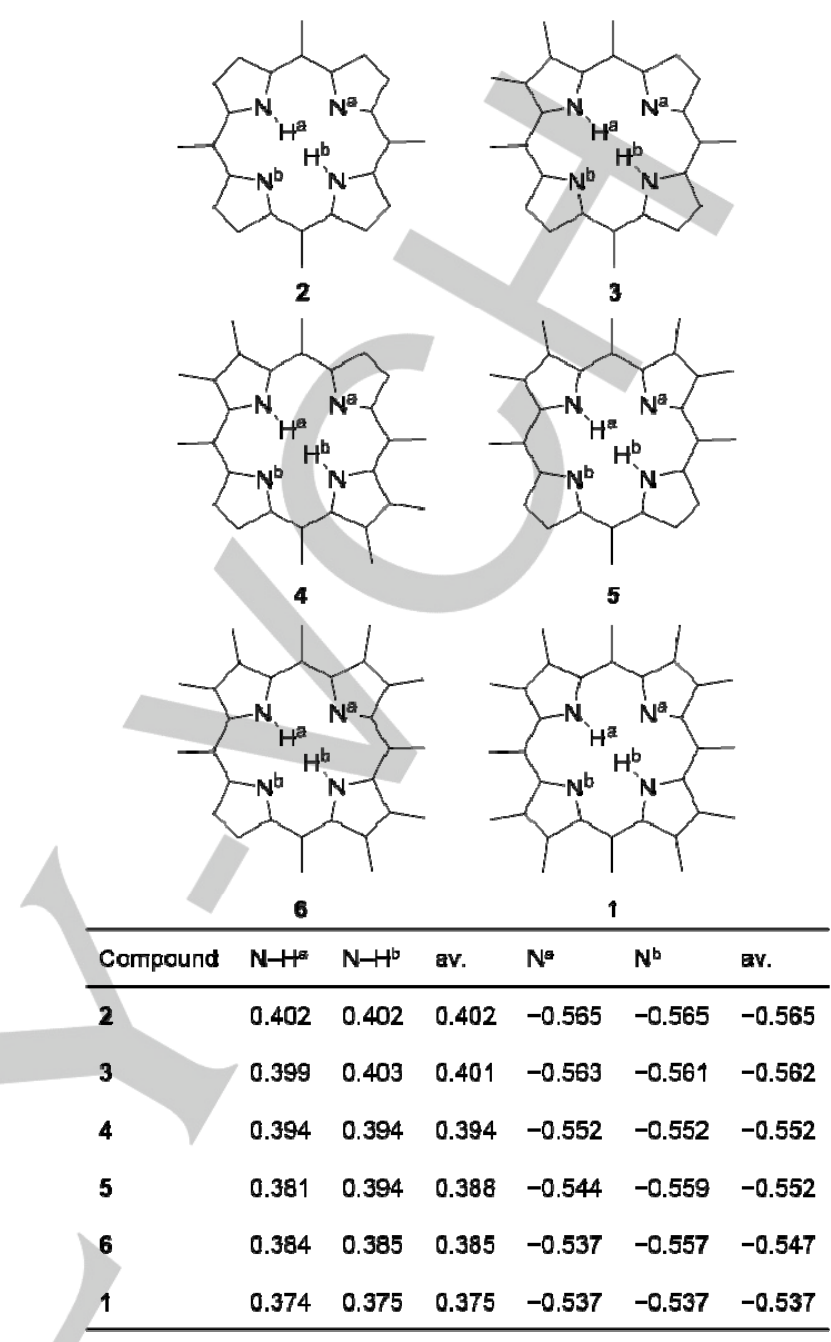

Figure 3. Calculated charge densities (Mulliken charges) of the $\mathrm{N}^{\mathrm{a} / \mathrm{b}} / \mathrm{N}-\mathrm{H}^{\mathrm{a} / \mathrm{b}}$ atoms in porphyrins 1-6.

\section{Conclusions}

Applying a series of six $\beta$-substituted ' $\mathrm{H}_{2} \mathrm{Et}_{\mathrm{x}}$ TPPs' 1-6 as potential organocatalysts in sulfa-Michael reactions allowed us to trace the incremental introduction of catalytic activity into the porphyrins. This was shown in a catalyst screening where increasing conversions were noted. We ascribe this behavior to an escalating saddle-type distortion of the compounds as a form of molecular engineering. As is well documented, saddle-type nonplanarity increases the vector of all inner core $\mathrm{N} / \mathrm{N}-\mathrm{H}$ entities outwards and, as we have shown through DFT calculations, results in some degree of modification of the groups' electronic properties. While the applied DFT model falls short of supporting the observed increase in catalytic activity, conformational analysis of the title compounds strongly supports the findings. Nevertheless, both electronic and steric factors in nonplanar porphyrins are usually tied inseparable and it is evident that both are prerequisites for the design of future porphyrin organocatalysts. Conclusively, a combination of modulating 
electronic properties and conformations in tetrapyrroles stands at the base of a new generation of bifunctional organocatalysts with great potential for tunability.

\section{Experimental Section}

Porphyrins 1-6 were synthesized according to the literature. ${ }^{[7]}$ For small amounts of material, microliter syringes and an analytical balance were used. All reactions were carried out in 1 $\mathrm{mL}$ screw-cap vials $\left(\mathrm{c}_{\text {[cat.] }}=7.1 \cdot 10^{-2} \mathrm{M}\right)$ or $5 \mathrm{~mL}$ round-bottom flasks $\left(c_{\text {[cat.] }}=3.6 \cdot 10^{-3} \mathrm{M}\right)$ under a protective argon atmosphere. All solvents used were degassed and dried over $\mathrm{Al}_{2} \mathrm{O}_{3}$. The nucleophile (43.8 $\mu \mathrm{L} ; 7.05 \cdot 10^{-2} \mathrm{mmol} ; 1.0$ equiv.), catalyst (e.g., $5.92 \mathrm{mg}$ for $2 ; 7.05 \cdot 10^{-3} \mathrm{mmol} ; 3 \mathrm{~mol} \%$ ), and Michael acceptor (43.5 mg; 7.76.10-2 mmol; 1.1 equiv.) were dissolved in $\mathrm{CH}_{2} \mathrm{Cl}_{2}$ ( 0.1 or $2 \mathrm{~mL}$, according to Table 2 ) and the mixture was stirred in the dark at RT for $24 \mathrm{~h}$. For each reaction, a blank sample without catalyst was set up, too. At the end of each reaction, the internal standard $\left(\mathrm{CH}_{2} \mathrm{Br}_{2}, 8.25 \mu \mathrm{L} ; 3.53 \cdot 10^{-2} \mathrm{mmol} ; 0.5\right.$ equiv.) was added into the reaction mixture and a ${ }^{1} \mathrm{H}$ NMR spectrum was recorded. The conversion was determined via quantitative ${ }^{1} \mathrm{H}$ NMR by comparison of the product integrals with the integrals of the internal standard.

Theoretical calculations were performed using $\mathrm{DFT}^{[18]}$ with Becke's three-parameter hybrid exchange functional (B3) $)^{[19]}$ and the Lee-Yang-Parr correlation functional (LYP), ${ }^{[20]}$ collectively abbreviated as B3LYP. Pople's split-valence double-zeta basis set, i.e. 6-31G (d,p) was used for the macrocyclic core atoms $(C$, $\mathrm{H}, \mathrm{N}$ ) in all cases. ${ }^{[21]}$ To confirm the potential energy minima, analytical frequency calculations were carried out for the optimized geometries. Gaussian 09 (G09) was used to execute the DFT calculations. ${ }^{[22]}$ The polarizable continuum model (PCM) was used to elucidate the solvent effects for $\mathrm{CH}_{2} \mathrm{Cl}_{2} .{ }^{[23]} \mathrm{DFT}$ calculations $^{[18]}$ were carried out without any symmetry restrictions. Mulliken charge analysis was performed using above-mentioned functional and basis set in $\mathrm{CH}_{2} \mathrm{Cl}_{2}{ }^{[24]}$

\section{Acknowledgments}

This work was supported by a grant from Science Foundation Ireland (SFI IvP 13/IA/1894).

Keywords: hydrogen bonds $\cdot$ macrocycles $\cdot$ molecular engineering $\bullet$ organocatalysis $\bullet$ porphyrins

[1] a) M. Kielmann, C. Prior, M. O. Senge, New. J. Chem. 2018, 42, 75297550; b) Y. Ding, W.-H. Zhu, Y. Xie, Chem. Rev. 2017, 117, 2203 2256; c) Q. Zou, M. Abbas, L. Zhao, S. Li, G. Shen, X. Yan, J. Am. Chem. Soc. 2017, 139, 1921-1927; d) J. Rawson, A. C. Stuart, W. You, M. J. Therien, J. Am. Chem. Soc. 2014, 136, 17561-17569; e) M. Ethiranjan, Y. Chen, P. Joshi, R. K. Pandey, Chem. Soc. Rev. 2011, 40, 340-362; f) M. O. Senge, Chem. Commun. 2011, 47, 1943-1960.

[2] a) S. Hiroto, Y. Miyake, H. Shinokubo, Chem. Rev. 2017, 117, 2910 3043; b) M. O. Senge, S. A. MacGowan, Chem. Commun. 2015, 51, 17031-17063; c) M. Ravikanth, T. K. Chandrashekar, Struct. Bonding 1995, 82, 105-188; d) J. Takeda, T. Ohya, M. Sato, Inorg. Chem. 1992
31, 2877-2880; e) J. A. Shelnutt, X.-Z. Song, J.-G. Ma, S.-L. Jia, W. Jentzen, C. J. Medforth, Chem. Soc. Rev. 1989, 27, 31-42.

[3] a) M. O. Senge, M. W. Renner, W. W. Kalisch, J. Fajer, J. Chem. Soc., Dalton Trans. 2000, 381-385; b) J. A. Hodge, M. G. Hill, H. B. Gray, Inorg. Chem. 1995, 34, 809-812; c) P. Bhyrappa, M. Nethaji, V. Krishnan, Chem. Lett. 1993, 22, 869-872.

[4] M. O. Senge, Chem. Commun. 2006, 243-256.

[5] R. Paolesse, S. Nardis, D. Monti, M. Stefanelli, C. Di Natale, Chem. Rev. 2017, 117, 2517-2583.

[6] a) M. Kielmann, M. O. Senge, Angew. Chem. Int. Ed. in press, DOI: 10.1002/anie.201806281; b) M. Roucan, M. Kielmann, S. J. Connon, S S. R. Bernhard, M. O. Senge, Chem. Commun. 2018, 54, 26-29; c) M. O. Senge, I. Bischoff, Eur. J. Org. Chem. 2001, 1735-1751.

[7] a) M. O. Senge, W. W. Kalisch, Inorg. Chem. 1997, 36, 6103-6116; b) W. W. Kalisch, M. O. Senge, Tetrahedron Lett. 1996, 37, 1183-1186.

[8] C. J. Medforth, M. O. Senge, K. M. Smith, L. D. Sparks, J. A. Shelnutt, J. Am. Chem. Soc. 1992, 114, 9859-9869.

[9] M. O. Senge in The Porphyrin Handbook, Vol. 1 (Eds.: K. M. Kadish, K. M. Smith, R. Guilard), Academic Press, New York, 1999, pp. 239-347.

[10] a) M. Kielmann, K. J. Flanagan, K. Norvaiša, D. Intrieri, M. O. Senge, J. Org. Chem. 2017, 82, 5122; b) M. O. Senge, W. W. Kalisch, S. Runge, Tetrahedron 1998, 54, 3781-3798; c) N. Chaurdhri, N. Grover, M. Sankar, Inorg. Chem. 2018, 57, 6658-6668.

[11] K. M. Barkigia, M. W. Renner, L. R. Furenlid, C. J. Medforth, K. M. Smith, J. Fajer, J. Am. Chem. Soc. 1993, 115, 3627-3635.

[12] a) I. K. Thomassen, L. J. McComick, A. Ghosh, Cryst. Growth. Des 2018, 18, 4257-4259; b) K. E. Thomas, L. J. McCormick, H. VazquezLima, A. Ghosh, Angew. Chem. Int. Ed. 2017, 56, 10088-10092; c) M. O. Senge, ECS Trans. 2015, 66, 1-10; d) D. B. Berezin, Koord. Khim. 2007, 33, 476-480; Russ. J. Coord. Chem. 2007, 33, 466-470; e) M. O. Senge, Z. Naturforsch. 1999, 54b, 821-824; f) Y. Furusho, T. Kimura, Y. Mizuno, T. Aida, J. Am. Chem. Soc. 1997, 119, 5267-5268; g) M. O. Senge, T. P. Forsyth, L. T. Nguyen, K. M. Smith, Angew. Chem. Int. Ed. Engl. 1995, 33, 2485-2487; h) A. Regev, T. Galili, C. J. Medforth, K. M. Smith, K. M. Barkigia, J. Fajer, H. Levanon, J. Phys. Chem. 1994, 98 2520-2526.

[13] A. B. J. Parusel, T. Wondimagegn, A. Ghosh, J. Am. Chem. Soc. 2000, 122, 6371-6374.

[14] S. J. Silvers, A. Tulinsky, J. Am. Chem. Soc. 1967, 89, 3331-3337.

[15] a) A. Ghosh in The Porphyrin Handbook, Vol. 7 (Eds.: K. M. Kadish, K. M. Smith, R. Guilard), Academic Press, New York, 1999, pp. 1-38; b) A. Ghosh, Acc. Chem. Res. 1998, 31, 189-198.

[16] The data was downloaded from the Cambridge Crystallographic Data Centre (CCDC) 2018 using ConQuest version 1.23: a) C. R. Groom, I. J. Bruno, M. P. Lightfoot, S. C. Ward, Acta Cryst. 2016, B72, 171-179; b) I. J. Bruno, J. C. Cole, P. R. Edgington, M. Kessler, C. F. Macrae, P. McCabe, J. Pearson, R. Taylor, Acta Cryst. 2002, B58, 389-397.

[17] O. S. Finikova, A. V. Cheprakov, P. J. Carroll, S. Dalosto, S. A. Vinogradov, Inorg. Chem. 2002, 41, 6944-6946.

[18] R. G. Parr, W. Yang, Density Functional Theory of Atoms and Molecules, Oxford University Press, Oxford, UK, 1989

[19] A. D. Becke, J. Chem. Phys. 1993, 98, 5648-5652.

[20] C. Lee, W. Yang, R. G. Parr, Phys. Rev. B 1988, 37, 785-789.

[21] a) A. J. Wallace, D. L. Crittenden J. Phys. Chem. A 2014, 118, 21382148; b) W. J. Hehre, R. Ditchfield, J. A. Pople, J. Chem. Phys. 1972 , 56, 2257-2261.

[22] M. J. Frisch, G. W. Trucks, H. B. Schlegel, G. E. Scuseria, M. A. Robb, J. R. Cheeseman, G. Scalmani, V. Barone, B. Mennucci, G. A Petersson, H. Nakatsuji, M. Caricato, X. Li, H. P. Hratchian, A. F. Izmaylov, J. Bloino, G. Zheng, J. L. Sonnenberg, M. Hada, M. Ehara, K Toyota, R. Fukuda, J. Hasegawa, M. Ishida, T. Nakajima, Y. Honda, O. Kitao, H. Nakai, T. Vreven, J. A. Montgomery Jr, J. E. Peralta, F. Ogliaro, M. Bearpark, J. J. Heyd, E. Brothers, K. N. Kudin, V. N. Staroverov, R. Kobayashi, J. Normand, K. Raghavachari, A. Rendell, J. C. Burant, S. S. lyengar, J. Tomasi, M. Cossi, N. Rega, J. M. Millam, M. 
Klene, J. E. Knox, J. B. Cross, V. Bakken, C. Adamo, J. Jaramillo, R. Gomperts, R. E. Stratmann, O. Yazyev, A. J. Austin, R. Cammi, C. Pomelli, J. W. Ochterski, R. L. Martin, K. Morokuma, V. G. Zakrzewski, G. A. Voth, P. Salvador, J. J. Dannenberg, S. Dapprich, A. D. Daniels,
O. Farkas, J. B. Foresman, J. V. Ortiz, J. Cioslowski, D. J. Fox, Gaussian 09, Revision A.02, Gaussian, Inc., Wallingford CT, 2009.

[23] V. Barone, M. Cossi, J. Phys. Chem. A 1998, 102, 1995-2001.

[24] R. S. Mulliken, J Chem. Phys. 1955, 23, 1833-1840. 
Entry for the Table of Contents (Please choose one layout)

Layout 2:

\section{FULL PAPER}

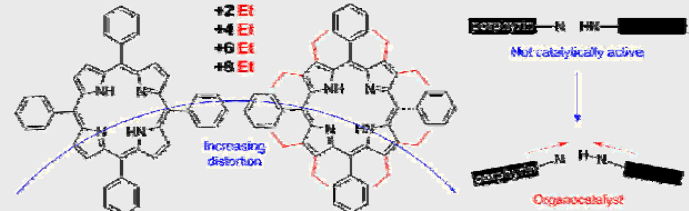

To study the correlation of macrocycle nonplanarity and catalytic activity of free base porphyrins in detail, a series of six tetraphenylporphyrins with graded degree of $\beta$-ethyl substitution was applied in organocatalyzed reactions. This was aided by DFT calculations in order to explain the distinct relationship between distortion and catalytic competence.

\section{Organocatalysis, Porphyrins}

M. Kielmann, N. Grover, W. W. Kalisch, M. O. Senge*

Page No. - Page No.

Incremental Introduction of Organocatalytic Activity into Conformationally Engineered Porphyrins 